\title{
Papaya Ringspot Virus Coat Protein Gene for Antigen Presentation in Escherichia coli
}

\author{
Supawat Chatchen ${ }^{1}$, Míla Jurícek ${ }^{2}$, Paloma Rueda ${ }^{3}$ and Sunee Kertbundit ${ }^{1,2, *}$ \\ ${ }^{1}$ Institute of Molecular Biology and Genetics, Mahidol University, Salaya Campus, Nakon Pathom 73170, Thailand \\ ${ }^{2}$ Institute of Experimental Botany, Czech Academy of Sciences, Na Pernikarce 15, 16000 Prague 6, Czech Republic \\ ${ }^{3}$ Ingenasa, Hermanos Garcia Noblejas 41-2, 28037 Madrid, Spain, Inmunologia y Genetica Apl. S.A. (INGENASA), \\ Hnos. Noblejas 41, 4 degrees, 28037, Madrid, Spain
}

Received 18 May 2005, Accepted 19 August 2005

\begin{abstract}
The coat protein (CP) of Papaya ringspot virus (PRSV) was analyzed for presentation of the antigenic peptide of animal virus, Canine parvovirus (CPV), in Escherichia coli ( $E$. coli). The 45 nucleotides fragment coding for the 15-aa peptide epitope of the CPV-VP2 protein was either inserted into the PRSV-cp gene at the 5', 3' ends, both 5' and $3^{\prime}$ 'ends or substituted into the 3 ' end of the PRSV cp gene. Each of the chimeric PRSV cp genes was cloned into the pRSET $B$ vector under the control of the T7 promoter and transformed into $E$. coli. The recombinant coat proteins expressed from different chimeric PRSV-cp genes were purified and intraperitoneally injected into mice. All of the recombinant coat proteins showed strong immunogenicity and stimulate mice immune response. The recombinant coat proteins containing the $C P V$ epitope insertion at the $C$ terminus and at both $\mathrm{N}$ and $\mathrm{C}$ termini elicited ten times higher specific antisera in immunized mice compared with the other two recombinant coat proteins which contain the CPV epitope insertion at the $\mathrm{N}$ terminus and substitution at the $\mathrm{C}$ terminus.
\end{abstract}

Keywords: Antigen presentation, Canine parvo virus, Epitope, Papaya ringspot virus

\section{Introduction}

Several plant viruses have been used as efficient presentation systems for expressing antigenic peptides or epitopes (Usha et al., 1993; Fitchen et al., 1995; Turpen et al., 1995; Joelson et al., 1997; Johnson et al., 1997; Sugiyama et al., 1997;

*To whom correspondence should be addressed.

Tel: 66-2-800-3624 ext 1376; Fax: 66-2-441-9906

E-mail: kertbundit@ueb.cas.cz
Yusibov et al., 1997; Koprowski and Yusibov, 2001). Epitopes are short peptides that contain antigenic determinants and can stimulate the immune response against the pathogen from which they are derived. The fusion of an epitope to a large carrier molecule such as the coat protein (CP) of plant virus could enhance the immunogenicity and stability of the epitope (Fitchen et al., 1995). The CP of potyvirus has been demonstrated as a good candidate of carrier molecule for presenting epitope (Jagadish et al., 1993; Fernandez-Fernandez et al., 1998, 2001). Experiments with Johnson grass mosaic potyvirus by Jagadish et al. (1996) revealed that hybrid CPs containing either short peptides or large target antigens fused at the N- or C-termini retained the ability to assemble into chimeric potyvirus-like particles (PVLPs). The chimeric PVLPs were highly immunogenic in mice and rabbits (Jagadish et al., 1996).

Papaya ringspot virus (PRSV) is a member of the genus Potyvirus. It is grouped into two types; type $\mathrm{P}$ (for papaya) infects both papaya and cucurbits (e.g. squash, pumpkin, cucumber, watermelon) while type $\mathrm{W}$ infects only cucurbits. (Tennant et al., 1994; Gonsalves, 1998). The complete nucleotide sequences of several strains of PRSV have been determined (Yeh et al., 1992; Attasart et al., 2002; Charoensilp et al., 2003). Similar to other potyviruses, the genome of PRSV consists of positive polarity single stranded RNA of about 10 kb surrounded by $\sim 2,000$ subunits of CP (Shukla et al., 1989). The $\mathrm{N}$ and $\mathrm{C}$ termini of the potyvirus $\mathrm{CP}$ are exposed at the surface of virions and are reported to be highly immunogenic (Shukla et al., 1988).

Canine parvovirus (CPV) is a member of the genus Parvovirus (Siegl et al., 1985). It caused a sudden outbreak of severe acute enteric disease in many species of dogs around the world (Apple et al., 1979, Burtonboy et al., 1979). The VP2 protein is the major structural protein of CPV (Tsao et al., 1991). The peptide 6L15 epitope at the N-terminal domain of the VP2 protein has been used to induce the CPV specific neutralizing antibodies against CPV (Casal et al., 1995) and 
had been expressed in plum pox potyvirus (FernandezFernandez, et al., 1998).

In this present study we analyzed the ability of using the PRSV CP as a carrier molecule for CPV epitope expression in $E$. coli. The expression plasmids containing the $c p$ gene of the PRSV with the insertion and substitution of the 6L15 epitope sequence at different positions of the $c p$ gene were constructed. The recombinant coat proteins expressed in the $E$. coli were purified and used to induce immune response in mice. The immunogenicity of the expressed epitope was reported.

\section{Materials and Methods}

Bacterial strain and plasmids. Escherichia coli strain BL21(DE3) pLysS (Studier 1991) was used for plasmid transformation. Plasmid pRSET B expression vector (Invitrogen) was used for cloning and expression of PRSV $c p$ gene and recombinant $c p$ genes.

Construction of $\mathrm{CP}$ and recombinant CP:CPV expression vectors. The intact $c p$ gene was amplified from the cDNA of PRSV type $\mathrm{P}$ by PCR reaction using CP-F/CP-R primers (Table 1 ). The recombinant $c p$ genes which contains the 45 nucletotides encoding the CPV 6L15 epitope inserted either at the 5', 3' or both 5' and 3' ends were obtained by PCR amplification using CPV-F/CP-R, CP-F/CPV-R or CPV-F/CPV-R primers (Table 1). The amplified DNA fragments of the intact $c p$ gene and the recombinant $c p$ genes were cloned into the pRSET B expression vector at the NcoI/ Hind III positions after the $\mathrm{T} 7$ promoter. Plasmid CP contains the native $c p$ gene while plasmids $\mathrm{CP} 1, \mathrm{CP} 2$ and $\mathrm{CP} 3$ contain the DNA sequence coding for $6 \mathrm{~L} 15$ epitope inserted to the $c p$ gene at the 5', 3' and both 5' and 3' ends, respectively. These plasmids were transformed into E. coli. BL21 (DE3) pLysS.

In order to substitute the 6L15 epitope sequence for the sequence located at the $3^{\prime}$ end of the $c p$ gene (nt 9,986 to 10,030 in the PRSV type P RNA sequence), the amplified intact $c p$ gene was blunt, digested with HindIII and inserted into the pUC19 vector at the Smal/HindIII sites. The recombinant $c p$ gene with the $6 \mathrm{~L} 15$ epitope sequence substitution at the 3 ' end was obtained by PCR amplification of the $c p$ gene using the $\mathrm{CP}-\mathrm{CPV} / \mathrm{CP}-\mathrm{R}$ primers. The amplified fragment was used to replace the Pst//HindIII fragment of the intact $c p$ gene in the pUC19 vector. The recombinant $c p$ gene was digested with $\mathrm{NcoI} / \mathrm{Hind} \mathrm{III}$ and cloned into the pRSETB expression vector to yield plasmid $\mathrm{CP} 4$. This plasmid was transformed into $E$. coli. BL21(DE3) pLysS.

Sodium Dodecyl Sulfate Polyacrylamide gel electrophoresis. The SDS-PAGE was performed to determine the expressed protein from recombinant clones according to the procedure previously described by Laemmli (Laemmli, 1970). Gels were stained with Coomassie brilliant blue R-250 solution and destained with $10 \%$ acetic acid and $10 \%$ methanol.

Purification of fusion CP-CPV proteins from $\boldsymbol{E}$. coli. The recombinant clone was grown at $37^{\circ} \mathrm{C}$ in $50 \mathrm{ml} \mathrm{LB}$ broth containing $100 \mu \mathrm{g} / \mathrm{ml}$ of ampicillin and $34 \mu \mathrm{g} / \mathrm{ml}$ of chloramphenicol. When the culture reached $\mathrm{OD}_{600}$ of 0.4-06, the protein expression was induced by adding $0.1 \mathrm{mM}$ IPTG and the culture was grown at $30^{\circ} \mathrm{C}$ for $4 \mathrm{~h}$. Bacterial cells were collected by centrifugation at $6,000 \times \mathrm{g}$ for $5 \mathrm{~min}$ at $4^{\circ} \mathrm{C}$ and resuspended in $5 \mathrm{ml}$ of start buffer ( $20 \mathrm{mM}$ sodium phosphate, $0.5 \mathrm{M} \mathrm{NaCl} \mathrm{pH} \mathrm{9.0).} \mathrm{The} \mathrm{cell} \mathrm{suspensions}$ were kept in ice bath and disrupted by a French Press. The cell lysates were centrifuged at $12,000 \times \mathrm{g}$ for $15 \mathrm{~min}$ at $4^{\circ} \mathrm{C}$. The fusion protein was separated from the supernatant by HiTrap affinity column (Amersham Pharmacia Biotech) according to the manufacturer's instruction. The supernatant was applied into the column prepared with $\mathrm{Ni}^{+2}$ ions. The loaded column was washed with wash buffer containing $25 \mathrm{mM}$ imidazole. The bound protein was eluted by $2 \mathrm{ml}$ of elution buffer containing $150 \mathrm{mM}$ imidazole. The protein concentration was measured by Bradford Protein assay (Bio-Rad).

Western blot analysis. The purified fusion proteins were analyzed by SDS-PAGE and blot transferred onto a nitrocellulose membrane $\left(\right.$ PROTRAN $^{\circledR}$ ) by semi-dry method using Trans-Blot ${ }^{\circledR}$ SD Electrophoretic Transfer Cell (BIO-RAD). The nitrocellulose membrane was rinsed for 3 times with $100 \mathrm{ml}$ of phosphatebuffered saline (PBS) and incubated with blocking solution (5\% skim milk and $0.2 \%$ Tween 20 in PBS) for $1 \mathrm{~h}$. The blocked membrane was subject to incubation with blocking solution

Table 1. Oligonucleotide primers used for PCR amplification. The Nco I/Hind III restriction sites are underlined. The 45 nucleotides coding for the $6 \mathrm{~L} 15$ epitope of CPV are presented in italic

\begin{tabular}{|c|c|}
\hline Primer name & Nucleotide sequences \\
\hline $\mathrm{CP}-\mathrm{F}$ & $\begin{array}{l}N c o \text { I } \\
\text { 5'-CATGCCATGGACCAGTCCAAAAATGAAGCTGTGG-3' }\end{array}$ \\
\hline $\mathrm{CP}-\mathrm{R}$ & $\begin{array}{l}\text { HindIII } \\
\text { 5'-CCCAAGCTTCAATTGCGCATACCCAGGAGAG-3' }\end{array}$ \\
\hline CPV-F & $\begin{array}{l}\text { NcoI } \\
\text { 5'-CATGCCATGGTTCAACCAGACGGTGGTCAACCTGCTGTCAGAAATGAAAGAGCT } \\
\text { CAGTCCAAAAATGAAGCTGTGGATGC-3' }\end{array}$ \\
\hline CPV-R & $\begin{array}{l}\text { HindIII } \\
\text { 5'-CCCAAGCTTCAAGCTCTTTCATTTCTGACAGCAGGTTGACCACCGTCTGGTTGAAC } \\
\text { ATTGCGCATACCCAGGAGAGAGTGC-3' }\end{array}$ \\
\hline CP-CPV & $\begin{array}{l}\text { PstI } \\
\text { 5'AAAGCTGCAGTTCAACCAGACGGTGGTCAACCTGCTGTCAGAAATGAACGCGCG } \\
\text { GTCAGTAACAAGGAAGAAAACACG 3' }\end{array}$ \\
\hline
\end{tabular}


containing $1: 1,000$ dilution of primary antibody for $1 \mathrm{~h}$. The antiCPV monoclonal antibody 3C9 (Ingenasa) was used as primary antibody for detection of the 6L15 epitope of CPV VP2 antigen. After one hour incubation with the primary antibody, the membrane was incubated in the blocking solution containing the $1: 5,000$ dilution of secondary antibody (anti-mouse IgG conjugated with horseradish peroxidase) for $1 \mathrm{~h}$. The peroxidase reaction was developed using the ECL plus western blotting detection reagent (Amersham Pharmacia Biotech) according to the manufacturer's instruction.

Immunization of mice. Groups of three 5-week-old mice strain $\mathrm{BALB} / \mathrm{c}$ were immunized intraperitoneally. Eighty microgram of either PRSV CP or purified fusion proteins was emulsified with Freud's complete adjuvant (Sigma) and used for the primary immunization on the day 0 . The booster immunization was performed on day 21 using the same amount of purified fusion protein emulsified with incomplete adjuvant. Mice were tail bled on day 0 before immunization and on days 35 and 42. The sera from immunized mice in the same group were pooled and used for NCM-ELISA.

Analysis of antibodies by NCM-ELISA. Sera recovered from immunized mice were analyzed by NCM-ELISA for reactivity against the VP2 antigen of CPV. The 1-1000 ng of VP2 antigen was loaded onto nitrocellulose membranes. The membrane was soaked in blocking solution (5\% skim milk and $0.2 \%$ Tween 20 in PBS) for $1 \mathrm{~h}$. The membrane was incubated in blocking solution containing $1: 500$ dilution of the primary polyclonal antibody obtained from each group of immunized mice at room temperature for $1 \mathrm{~h}$. The $1: 500$ dilution of anti-CPV monoclonal antibody 3C9 (Ingenasa) was used as positive control to detect the VP2 peptide. The membrane was washed 3 times with PBS-T and incubated with $1: 5,000$ dilution of secondary antibody (anti-mouse IgG conjugated with horseradish peroxidase) for $1 \mathrm{~h}$. The detection reagent (ECL plus western blotting detection reagent, Amersham Pharmacia Biotech) was used to develop the peroxidase reaction.

\section{Results}

Recombinant CP:CPV expression vectors. In order to evaluate the positions on the $c p$ gene of PRSV which are suitable for foreign protein expression, the 6L15 epitope sequence of the CPV was inserted and substituted into the $c p$ gene. Five $E$. coli BL21 clones containing the native $c p$ gene and recombinant $c p$ genes on the expression plasmids were generated (Fig. 1). Clone CP contains the native $c p$ gene while clone $\mathrm{CP} 1$ contains the epitope sequence insertion at the 5 'end after the start codon of the $c p$ gene. Clone CP2 contains the epitope sequence insertion at the $3^{\prime}$ end before the stop codon of the $c p$ gene and clone CP3 contains the epitope sequence insertion at both $5^{\prime}$ and $3^{\prime}$ ends. Clone $\mathrm{C} 4$ contains the epitope substitution at the $3^{\prime}$ end of the $c p$ gene.

Expression of PRSV-CP:CPV recombinant protein in $E$. coli. After induction with IPTG, E. coli BL21 clones harboring the pRSETB based recombinant plasmids efficiently produced

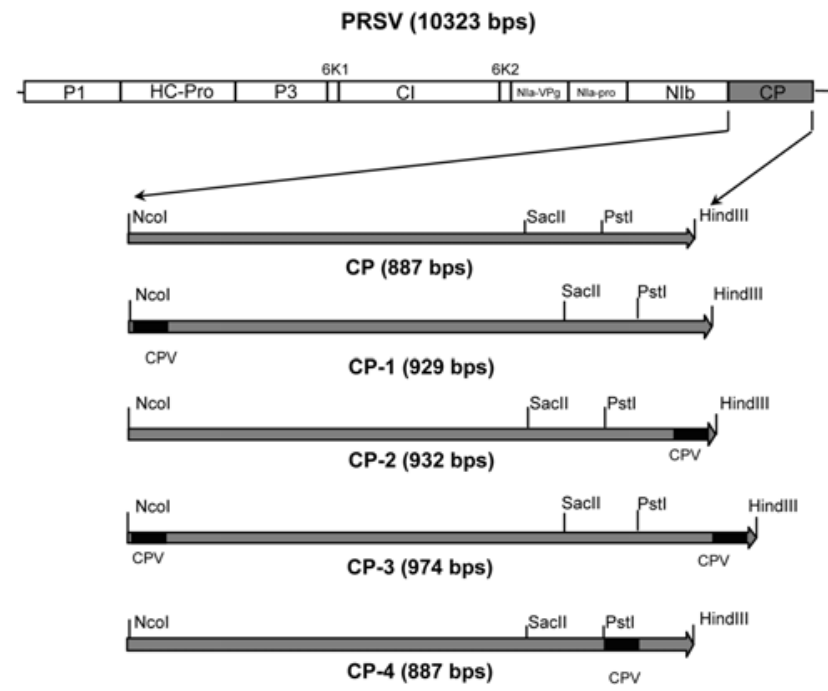

Fig. 1. Schematic representation of native PRSV-cp gene (CP) and chimeric $c p$-CPV constructs. The $\mathrm{CPV}$ epitope was inserted at the $5^{\prime}$ end (CP1), $3^{\prime}$ end (CP2), both $5^{\prime}$ and $3^{\prime}$ ends (CP3) and was substituted at the 3 'end (CP4) of the $c p$ gene. Black boxes indicate the positions of CPV epitope insertion and substitution on the PRSV-cp gene.

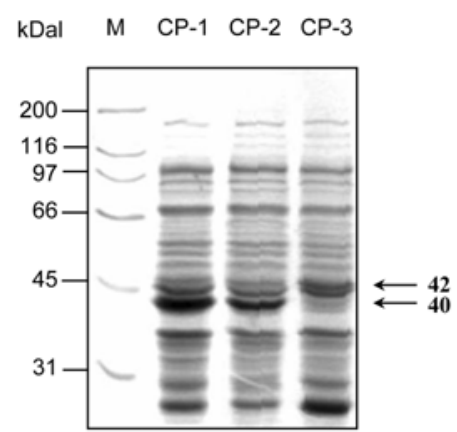

(A)

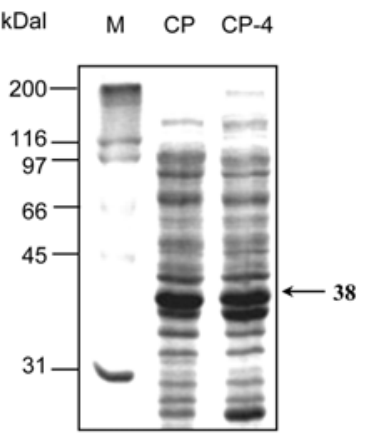

(B)
Fig. 2A and B. SDS-PAGE analysis of the expressed total proteins in E. coli BL21 clones harboring the pRSETB based recombinant plasmids after induction with IPTG. SDS-PAGE was performed using a $10 \%$ polyacrylamide gel and stained with Coomassie brilliant blue. Lane (M) is molecular mass markers.

recombinant proteins. The relative molecular weights of the native $\mathrm{CP}$ and the $\mathrm{CP}-4$ are $38 \mathrm{kD}$; the $\mathrm{CP}-1$ and the $\mathrm{CP}-2$ are about $40 \mathrm{kD}$ and the $\mathrm{CP}-3$ is $42 \mathrm{kD}$, as estimated by visual inspection of SDS-PAGE, which were consistent with size of native $\mathrm{CP}$ and the inserted size of epitope in each constructs. (Fig. 2A and $\mathrm{B}$ ). Both of the native and recombinant CPs were present in the pellet and were insoluble. The protein aggregates were dissociated into the soluble fraction by dissolving with sodium-phosphate buffer $\mathrm{pH} 9$ and purified by $\mathrm{Ni}^{2+}$ ions affinity column. The yield of the native and recombinant CPs after affinity column purification was approximately $80-200 \mu \mathrm{g} / \mathrm{l}$ of bacterial cultures. The purified recombinant CPs were specifically detected in western blot analysis using the anti-CPV monoclonal antibody 3C9 (Fig. 


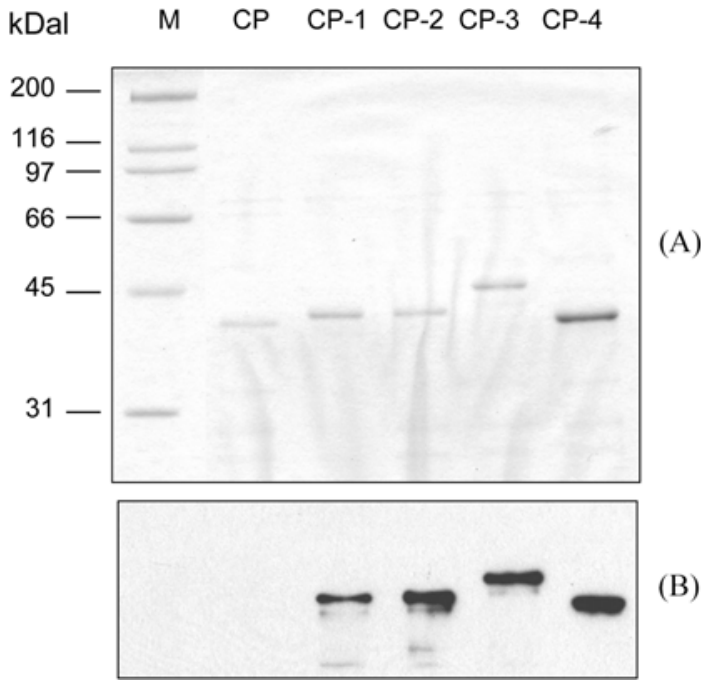

Fig. 3. Analysis of native $\mathrm{CP}$ and $\mathrm{CP}-\mathrm{CPV}$ fusion proteins. (A) Coomassie blue stained SDS-polyacrylamide gel displaying: molecular mass markers (M), native CP (CP), CP fusion proteins containing CPV epitope insertion at N-terminal CPV (CP-1), Cterminal $\mathrm{CP}$ (CP-2), at both $\mathrm{N}$ and $\mathrm{C}$-terminal (CP-3), and the CPV epitope substitution (CP-4). (B) Western blot analysis using anti-CPV MAb 3C9.

$3 \mathrm{~A}$ and $\mathrm{B})$, revealing that all recombinant proteins contain the CPV epitope. No cross reaction with the native $\mathrm{CP}$ was detected.

Immunogenicity of chimeric CP-CPV. The immunogenicity of recombinant proteins $\mathrm{CP}-1, \mathrm{CP}-2, \mathrm{CP}-3$ and $\mathrm{CP}-4$ were tested by BALB/c mice immunization. The purified native $\mathrm{CP}$ was used in control mice. The specificity and sensitivity of the antisera obtained from the immunized mice responded to the CPV VP2 antigen were evaluated in NCM- ELISA analysis (Fig. 4) and compared with the anti-CPV monoclonal antibody 3C9. There is no cross-reaction between the antiserum to the native $\mathrm{CP}$ with the CPV VP2 antigen. The antisera CP-2 and CP-3 showed the same sensitivity to detect as low as $10 \mathrm{ng}$ of CPV VP2 antigen which is about ten times less sensitive than the monoclonal antibody $3 \mathrm{C}$. The antisera $\mathrm{CP}-1$ and $\mathrm{CP}-4$ exhibited about ten times lower sensitivity than the antisera to the CP-2 and CP-3 as they can not detect the CPV VP2 protein at concentration lower than $100 \mathrm{ng}$. These results demonstrated that recombinants CPs are immunogenic when inoculated intraperitoneally into mice and there is no common antigenic part between the CPV VP2 antigen and the PRSV coat protein.

NCM-ELISA analysis of the reaction between the antisera and the partially purified PRSV particles indicated that all antisera can detect the partially purified PRSV particles at concentration of $1 \mathrm{ng}$ (Fig. 5). This result indicated that the PRSV CP part in all of the recombinant proteins can stimulate mouse immune response at the same level as the native CP. The monoclonal antibody 3C9 cannot react with the partially purified PRSV particles at concentration of $1000 \mathrm{ng}$ which

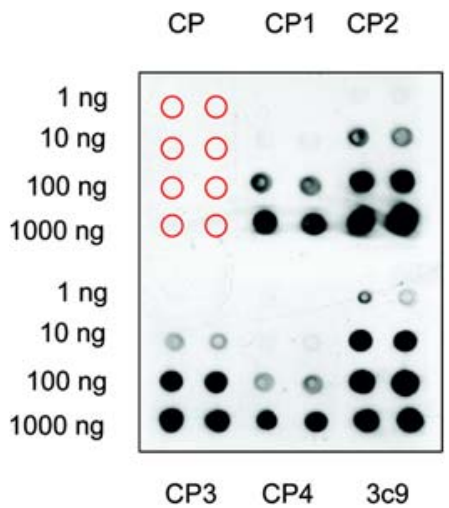

Fig. 4. NCM-ELISA analysis for the specificity and sensitivity of immunized sera against CPV VP2 antigen. The CPV VP2 antigen was spotted in duplicate on the nylon membrane at different amounts of 1, 10, 100 and $1000 \mathrm{ng}$. Each membrane was incubated with 1/500 dilution of each serum recovered from mice immunized with CP, CP-1, CP-2, CP-3, CP-4. The antiCPV MAb 3C9 antibody was used as a control.

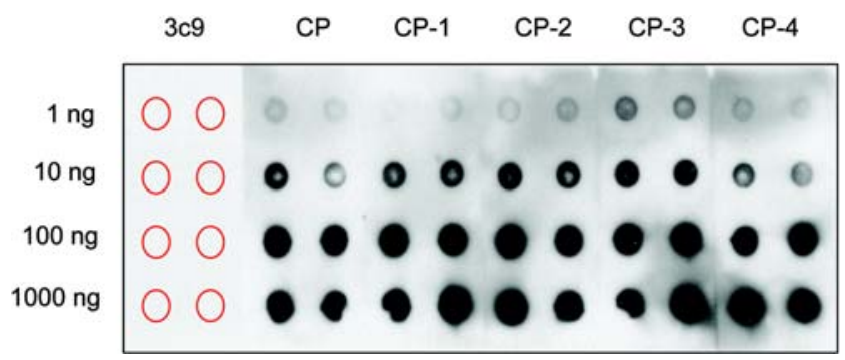

Fig. 5. NCM-ELISA analysis of immunized sera reactivity against PRSV particle. The PRSV particle was spotted in duplicate on the nylon membrane at different amounts of 1, 10, 100 and $1000 \mathrm{ng}$. Each membrane was incubated with 1/500 dilution of each serum recovered from mice immunized with $\mathrm{CP}$, CP-1, CP-2, CP-3, CP-4. The anti-CPV MAb 3C9 antibody was used as a control.

indicated that there is no common antigenic part between the CPV VP2 antigen and the PRSV viral particle.

\section{Discussion}

Potyvirus is a group of single stranded RNA viruses with rodshaped, self assemble in an ordered manner, and accumulates to high levels in infected tissues. The $\mathrm{CP}$ of potyvirus is a good candidate carrier molecule for epitope presentation. The potyvirus CP can express in heterologous host expression systems including bacterial, yeast or insect cell (Jagadish et al., 1996).

In this study, the effectiveness of using the CP of PRSV as an antigen presentation system in E. coli is reported. The recombinant $c p$ genes containing the $6 \mathrm{~L} 15$ epitope sequence at several positions were constructed and expressed in E. coli. The reactivity of the anti CPV monoclonal antibody $3 \mathrm{C} 39$ to 
all recombinant CPs in western blot analysis revealed the presence and accessibility of CPV epitope on the recombinant CPs. The epitope placed on N-or C- terminus or on both Nand $\mathrm{C}$ - termini can effectively induce the mouse immune response although the sensitivity of the antisera raised against the recombinant $\mathrm{CP}$ containing the epitope on the $\mathrm{N}$ - terminus is about 10 times lower than the recombinant CPs containing the epitope on the C-terminus or on both $\mathrm{N}$ - and $\mathrm{C}$ - termini. Recombinant CP with the substitution of the epitope on the C-terminus showed the same ability to raise the mouse immune response as the recombinant $\mathrm{CP}$ containing the epitope on the N-terminus. These results are in agreement with the result of potyvirus JGMV (Jagadish et al., 1993). The $\mathrm{CP}$ of JGMV can be fused with the epitopes either on the $\mathrm{N}$ and/or C-terminus without abolishing the ability of the protein to polymerize into virus-like particles when expressed in $E$. coli and can stimulate the mouse immune response. The decrease of the immunogenicity of the CPV epitope when inserted at the N-terminus of the PRSV CP or replacement with the amino acids on the C-terminus of the PRSV CP revealed that the position of the epitope presentation effects the immunogenicity. The identification of immunogenic hot spots within plum pox virus (PPV) coat protein by peptide scan showed that the N-terminal domain of the PPV CP is not uniformly immunogenic and some regions are preferentially recognized by sera (Fernandez-Fernandez et al., 2002). The result from our experiment indicated that epitope inserted at the position on the C-terminus of the PRSV CP can expose to the surface of the recombinant protein and trigger the mouse immune response more efficient than the epitope inserted at $\mathrm{N}$-terminus or the epitope substitution at the C-terminus. It is important to verify the appropriate position of the epitope insertion on the $\mathrm{CP}$ to get the high immunogenicity of the epitope.

Therefore, we have demonstrated here that the PRSV CP can be effectively used for antigen presentation to produce sufficient quantities of an animal viral antigen in E. coli. The recombinants PRSV CPs are successfully used to stimulate an animal immune response to the pathogen. The epitope production can easily amplify in sterile bacterial culture system. It is also possible to develop the PRSV infectious particle containing the chimeric CP to express epitope on the surface of the viral particle. The advantage of developing the infectious virus particle is the exclusion of sterile culture system. However there are some restrictions on the expression of foreign peptides on the $c p$ gene of some viral particles (Fernandez-Fernandez et al., 2002; Porta et al., 2003). Effect of the chimeric $c p$ on virus assembly, disassembly and stability will be important considerations for engineering the chimeric PRSV infectious virus.

Acknowledgment We thank Nuanwan Pungtanom and Aurathai Tanwanchai for assistances. This work was supported by the grant from BIOTEC, NASDA, Thailand, project code BT-B-06-PG-14-4503 and by the grant from Thai Research Fund, project code TRF-RDG4420016.

\section{References}

Appel, M. J. G., Scott, F. W. and Carmichael, L. E. (1979) Isolation and immunisation studies of a canine parvo-like virus from dogs with haemorrhagic enteritis. Vet. Rec. 105, 156-179.

Attasart, A., Charoensilp, G., Kertbundit, S., Panyim, S. and Juricek, M. (2002) Nucleotide sequence of Thai isolate of papaya ringspot virus type W. Acta Virologica 46, 241-246.

Burtonboy, G., Coignoul, F., Delferriere, N. and Pastoret, P. P. (1979) Canine hemorrhagic enteritis: detection of viral particles by electron microscopy. Arch. Virol. 61, 1-11.

Casal, J. I., Langeveld, J. P. M., Cortes, E., Schaaper, W. W. M., van Dijk, E., Vela, C., Kamstrup, S. and Meloen, R. H. (1995) Peptide vaccine against canine parvovirus: identification of two neutralization subsites in the $\mathrm{N}$ terminus of VP2 and optimization of the amino acid sequence. J. Virol. 69, 72747277.

Charoensilp, G., Attasart, A., Juricek, M., Panyim, S. and Kertbundit, S. (2003) Sequencing and characterization of Thai papaya ringspot virus isolate type P (PRSVthP). Science Asia 29, 89-94.

Fitchen, J., Beachy, R. N. and Hein, M. B. (1995) Plant virus expressing hybrid coat protein with added murine epitope elicits autoantibody response. Vaccine 13, 1051-1057.

Fernandez-Fernandez, M. R., Martinez-Torrecuadrada, J. L., Casal, J. I. and Garcia, J. A. (1998) Development of an antigen presentation system based on plum pox potyvirus. FEBS Lett. 427, 229-235.

Fernandez-Fernandez, M. R., Mourino, M., Rivera, J., Rodriguez, F., Plana-Duran, J. and Garcia, J. A. (2001) Protection of rabbits against rabbit hemorrhagic disease virus by immunization with the VP60 protein ex pressed in plants with a potyvirus-based vector. Virology 280, 283-291.

Fernandez-Fernandez, M. R., Martinez-Torrecuadrada, J. L., Roncal, F., Dominguez, E. and Garcia, J. A. (2002) Identification of immunogenic hot spots within plum pox potyvirus capsid protein for efficient antigen presentation. $J$. Virol. 76, 12646-12653.

Gonsalves, D. (1998) Control of papaya ringspot virus in papaya: a case study. Annu. Rev. Phytopathol. 36, 415-437.

Inoue, H., Nojima, H. and Okayama, H. (1990) High efficiency transformation of Escherichia coli with plasmids. Gene 96, 2328.

Jagadish, M. N., Hamilton, R. C., Fernandez, C. S., Schoofs, P., Davern, K. M., Kalnins, H., Ward, C. W. and Nisbet, I. T. (1993) High level production of hybrid potyvirus-like particles carrying repetitive copies of foreign antigens in Escherichia coli. BioTechniques 11, 1166-1170.

Jagadish, M. N., Edwards, S. J., Hayden, M. B., Grusovin, J., Vandenberg, K., Schoofs, P., Hamilton, R. C., Shukla, D. D., Kalnins, H., McNamara, M., Haynes, J., Nisbet , I. T., Ward, C. W. and Pye, D. (1996) Chimeric potyvirus-like particles as vaccine carriers. Intervirology 39, 85-92.

Joelson, T., Akerblom, L., Oxelfelt, P., Strandberg, B., Tomenius, K. and Morris, T. J. (1997) Presentation of a foreign peptide on the surface of tomato bushy stunt virus. J. Gen. Virol. 78, 1213-1217.

Johnson, J., Lin, T. and Lomonossoff, G. (1997) Presentation of heterologous peptides on plant viruses: genetics, structure, and function. Annu. Rev. Phytopathol. 35, 67-86. 
Koprowski, H. and Yusibov, V. (2001) The green revolution: plants as heterologous expression vectors. Vaccine 19, 27352741.

Laemmli, U. K. (1970) Cleavage of structural proteins during the assembly of the head of bacteriophage T4. Nature 227, 680685.

Porta, C., Spall, V. E., Kim, C., Findlay, K. C., Gergerich, R. C., Farrance, C. E. and Lomonossoff, G. P. (2003) Cowpea mosaic virus-based chimaeras Effects of inserted peptides on the phenotype, host range, and transmissibility of the modified viruses. Virology 310, 50-63.

Shukla, D. D., Strike, P. M., Tracy, S. L., Gough, K. H. and Ward, C. W. (1988) The N and C termini of the coat proteins of potyviruses are surface-located and the $\mathrm{N}$ terminus contains the major virus-specific epitopes. J. Gen. Virol. 69, 1497-1508.

Shukla, D. D. and Ward, C. W. (1989) Structure of potyvirus coat proteins and its application in the taxonomy of the potyvirus group. Adv. Virus Res. 36, 273-314.

Siegl, G., Bates, R. C., Berns, K. I., Carter, B. J., Kelly, D. C., Kurstak, E. and Tattersall, P. (1985) Characteristics and taxonomy of Parvoviridae. Intervirology 23, 61-73.

Studier, F. W. (1991) Use of bacteriophage T7 lysozyme to improve an inducible T7 expression system. J. Mol. Biol. 219, $37-44$.

Sugiyama, Y., Hamamato, H., Takemoto, S., Watanabe, Y. and Okada, Y. (1995) Systemic production of foreign peptides on the particle surface of tobacco mosaic virus. FEBS Lett. 359, 247-250.
Tsao, J., Chapman, M. S., Agbandje, M., Keller, W., Smith, K., Wu, H., Luo, M., Smith, T. J., Rossman, M. G., Compans, R. W. and Parrish, C. R. (1991) The three-dimensional structure of canine parvovirus and its functional implications. Science 251, 1456-1464.

Tennant, P., Gonsalves, C., Ling, K., Fitch, M., Manshardt, R., Slightom, J. and Gonsalves, D. (1994) Differential protection against papaya ringspot virus isolates in coat protein gene transgenic papaya and classically cross-protected tapaya. The Amer. Phytopathological Society 84, 1359-1366.

Turpen, T. H., Reinl, S. J., Charoenvit, Y., Hoffman, S. L., Fallarme, V. and Grill, L. K. (1995) Malarial epitopes expressed on the surface of recombinant tobacco mosaic virus. Biotechnology 13, 53-57.

Usha, R., Rohll, J. B., Spall, V. E., Shanks, M., Maule, A. J., Johnson, J. E. and Lomonossoff, G. P. (1993) Expression of an animal virus antigenic site on the surface of a plant virus particle. Virology 197, 366-374.

Yeh, S. D., Jan, F. J., Chiang, C. H., Doong, T. J., Chen, M. C., Chung, P. H. and Bau, H. J. (1992) Complete nucleotide sequence and genetic organization of papaya ringspot virus RNA. J. Gen. Virol. 73, 2531-2541.

Yusibov, V., Modelska, A., Steplewski, K., Agadjanyan, M., Weiner, D., Hooper, D. C. and Koprowski, H. (1997) Antigens produced in plants by infection with chimeric plant viruses immunize against rabies virus and HIV-1. Proc. Natl. Acad. Sci. USA 94, 5784-5788. 